\title{
Mix Design and Quality Control Procedures for High Mobility Cement Based Grouts
}

\author{
M. Chuaqui ${ }^{1}$ and D.A. Bruce ${ }^{2}$
}

\begin{abstract}
Measures of success for any grouting program should include superior technical performance and cost effectiveness. These can be achieved by designing grouts with properties that are specifically tailored to the application. This requires a fundamental understanding of the fluid and set performance characteristics needed for a specific application. For high mobility cement based grouts (HMG), these properties include bleed, segregation, resistance to pressure filtration, control of particle agglomeration, anti-washout characteristics, rheology, evolution of cohesion with time, set time, matrix porosity, ultimate strength, resistance to chemical attack, and durability. A description of how each property is quantified, evaluated and optimized is provided, and related to appropriate standards. A three-step process for the design and quality control of an HMG project is outlined. The first step is a laboratory-scale testing program to determine basic formulations, optimized for performance characteristics and cost. The second step is full-scale trial batching performed on site with the materials and equipment that will be used on the project. The third step is quality control testing during production grouting to ensure that the grouts being used are being batched correctly and will perform appropriately in situ. A digest of mix HMG designs used on recent projects is provided for illustration and reference.
\end{abstract}

${ }^{1}$ Principal, MC Grouting, Inc., 29 Haliburton Ave., Toronto, ON M9B 4Y5 Canada; Tel: (416) 695-2593; Fax: (416) 695 2399; email: marcelo.chuaqui@,sympatico.ca.

${ }^{2}$ President, Geosystems, L.P., P.O. Box 237, Venetia, PA 15367, U.S.A.;

Tel: (724) 942-0570; Fax: (724) 942-1911; email: dabruce@geosystemsbruce.com. 


\section{Introduction}

The term HMG refers to the family of high mobility cement based grouts. These have a rheology which is best measured by either a Marsh cone or flow cone and not by a slump cone. As opposed to low mobility grouts (LMG) (Byle, 1997), HMGs have a relatively low viscosity and therefore high mobility. A fundamental understanding of the performance characteristics required of a grout formulation is necessary to responsively design a grout for a specific application. Whereas HMGs traditionally comprised only cement and water, with the use of other materials such as sand or accelerator considered only in extreme conditions (e.g. "runaway" takes), recent years have seen major changes in grout mix formulation, especially in the United States. Routinely, projects are now employing suites of balanced, stable particulate grouts whose fluid and set properties are achieved by the use of multiple additives, as well as variations in the waster content and cement characteristics. Such HMGs are characterized by low bleed, superior resistance to pressure filtration, and controlled rheology.

The development of these HMGs on any particular project is best done in a threephase process. During the first phase, a series of formulations, each suited for injection under the specific site conditions, is developed through a laboratory-testing program. During the second phase, on site and prior to production, the mix designs are replicated to investigate any changes in properties due to differences in materials, mixing equipment or procedures between the laboratory testing and production grouting. During this phase the baseline data for the quality control program are also established. During the third phase, during production grouting, the properties of the grouts are verified regularly to ensure that grouts are being batched correctly.

This paper provides a summary of the key performance parameters for HMGs and how to measure them. The influence of the individual component materials is discussed, and is illustrated by reference to a digest of mixes used in recent projects in the United States.

\section{Evaluation of HMG Properties}

In order to responsively design a $\mathrm{HMG}$, it is necessary to understand what fluid and set properties are desirable. For different applications the relative importance of the properties will change, but in general the properties listed below are usually if not always desirable. Table 1 summarizes the standard quality control tests used in the field.

\subsection{Rheology and the Evolution of Apparent Viscosity and Cohesion with Time}

The rheology of an HMG is characterized by apparent viscosity, cohesion, and internal friction. Figure 1 depicts the behavior of Newtonian and Binghamian fluids. Water and true solution grouts behave as Newtonian fluids, while stable HMGs behave like Binghamian fluids. The behavior of both the fluids depicted in Figure 1 
reflects no internal friction. The behavior depicted in Figure 2 is characteristic of a grout with internal friction, and a shear strength that depends on fluid pressure. Unstable grouts behave unpredictably, acting alternatively as a Newtonian fluid and then as a Binghamian fluid with internal friction (Gause and Bruce, 1997). Fluids with high internal friction are not optimal for injection, as high pressures are required to pump them over significant distances.

Table 1. Standard Field Quality Control Tests for HMGs

\begin{tabular}{|c|c|c|}
\hline EQUIPMENT & TEST & DESCRIPTION \\
\hline Marsh Funnel & $\begin{array}{l}\text { Apparent } \\
\text { Viscosity }\end{array}$ & $\begin{array}{l}\text { The Marsh time of the grout can be measured in accordance with } \\
\text { the method described in API Recommended Practice } 13 \mathrm{~B}-1 \text { with a } \\
\text { Marsh funnel and a calibrated container. The test is performed by } \\
\text { filling the Marsh cone to the bottom of the dump screen and then } \\
\text { measuring the time for } 0.26 \text { gallons (1 liter) of grout to flow } \\
\text { through the funnel. }\end{array}$ \\
\hline $\begin{array}{l}\text { Penetrometer/ } \\
\text { or Shear Vane }\end{array}$ & $\begin{array}{l}\text { Cohesion } \\
\text { and Time to } \\
\text { Initial/Final } \\
\text { Gelation } \\
\end{array}$ & $\begin{array}{l}\text { Either a penetrometer or shear vane type test will be used to } \\
\text { measure the amount of time required for the grout to reach initial } \\
\text { gelation (cohesion of } 100 \mathrm{~Pa} \text { ) and final gelation (cohesion of } 1000 \\
\mathrm{~Pa} \text { ). }\end{array}$ \\
\hline $\begin{array}{l}\text { API Filter } \\
\text { Press }\end{array}$ & $\begin{array}{c}\text { Pressure } \\
\text { Filtration } \\
\text { Coefficient }\end{array}$ & $\begin{array}{l}\text { The pressure coefficient can be measured with an API filter press. } \\
\text { The test is performed by pouring a } 0.42 \text {-quarts }(400-\mathrm{ml}) \text { grout } \\
\text { sample into the top of the filter press. The sample is then } \\
\text { pressurized to } 0.7 \text { MPA. The test is run until all the water is } \\
\text { expelled from the sample. The value of the pressure filtration } \\
\text { coefficient is then calculated with the following equation: } \\
\left.\mathrm{K}_{\mathrm{pf}}=\quad \frac{\text { volume of filtrate }}{\text { volume of sample x (time in minutes) }}\right)^{(1 / 2)}\end{array}$ \\
\hline $\begin{array}{l}250-\mathrm{ml} \\
\text { Graduated } \\
\text { Cylinder - } \\
\quad \text { Glass }\end{array}$ & Bleed & $\begin{array}{l}\text { The bleed capacity of the grout can be measured in accordance } \\
\text { with the method ASTM C } 940 \text { with a } 0.26 \text {-quart }(250 \text {-ml) graduate } \\
\text { cylinder. The test is performed by pouring grout into the cylinder } \\
\text { to the } 0.21 \text {-quart }(200-\mathrm{ml}) \text { level. The sample is then left } \\
\text { undisturbed for two hours before the amount of bleed water is } \\
\text { measured. }\end{array}$ \\
\hline $\begin{array}{l}\text { Baroid Mud } \\
\text { Balance }\end{array}$ & $\begin{array}{l}\text { Specific } \\
\text { Gravity }\end{array}$ & $\begin{array}{l}\text { The specific gravity of a grout can be measured in accordance to } \\
\text { the method described in API Recommended Practice } 13 \mathrm{~B}-1 \text { with a } \\
\text { Baroid Mud Balance. The Baroid mud balance is a calibrated } \\
\text { scale that is used to measure the specific gravity. Micromotion } \\
\text { flow/density meters and hydrometers are also used in practice. }\end{array}$ \\
\hline Vicat Needle & $\begin{array}{c}\text { Initial and } \\
\text { Final Set } \\
\text { Times }\end{array}$ & $\begin{array}{l}\text { The initial and final set times can be determined with the Vicat } \\
\text { needle testing apparatus. The vicat needle is set at the surface of } \\
\text { the grout sample and released. Initial set is reached when the } \\
\text { needle only penetrates } 1 \text {-inch }(25-\mathrm{mm}) \text {. Final set is reached when } \\
\text { the needle does not penetrate the surface of the grout sample. }\end{array}$ \\
\hline
\end{tabular}

The cohesion (c) as shown in Figure 1, corresponds to the yield stress. The dynamic viscosity is shown by $\eta$, the plastic viscosity is shown by $\eta_{B}$ and the apparent viscosity is shown by $\eta$ '. The smaller the cohesion, the closer the plastic viscosity and the apparent viscosity are to each other. In the case of a Newtonian fluid, the cohesion is zero and the plastic viscosity and the apparent viscosity are equivalent and referred to as the dynamic viscosity. 
The cohesion controls how far a grout will penetrate an aperture of given radius at a specific pressure, while the viscosity determines the flow rate and the therefore the grouting time for an aperture of given radius at a specific pressure (Lombardi, 1985): $\mathrm{L} \alpha \mathrm{C}=(\mathrm{p} \times \mathrm{r}) /(2 \times \mathrm{C})$, where: $\mathrm{L}=$ length of the channel, $\mathrm{p}=$ the applied pressure, $\mathrm{r}$ $=$ radius of the channel, $\mathrm{C}=$ cohesion of the grout.

Therefore a low viscosity will optimize permeation grouting in a soil with small pores or a rock mass of fine fissures. Grouts for these applications should not however have so low a viscosity that they will travel long distances without appreciable pressure drop.

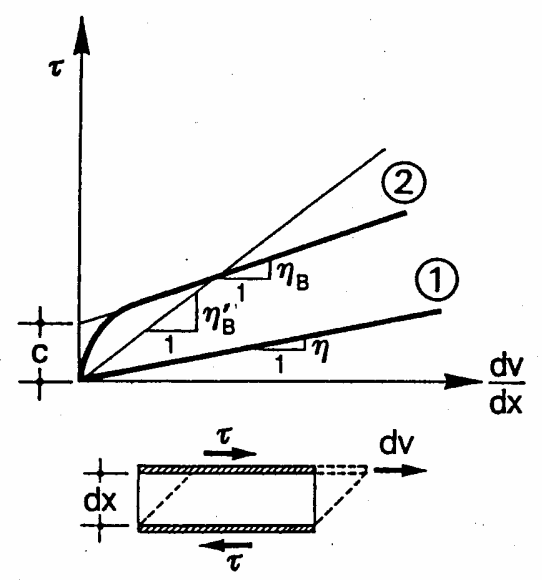

$$
\begin{aligned}
& \text { (1) } \tau=\eta \frac{d v}{d x} \\
& \text { (2) } \tau=c+\eta_{B} \frac{d v}{d x} \quad \simeq \eta^{\prime} \frac{d v}{d x} \\
& \eta=\text { dynamic viscosity } \\
& \eta_{B}=\text { plastic viscosity } \\
& \eta^{\prime}=\text { apparent viscosity } \\
& C=\text { cohesion or yield value }
\end{aligned}
$$

Figure 1: Rheological Behavior 1) Newtonian Fluid, 2 Binghamian Body

(De Paoli et al., 1992).

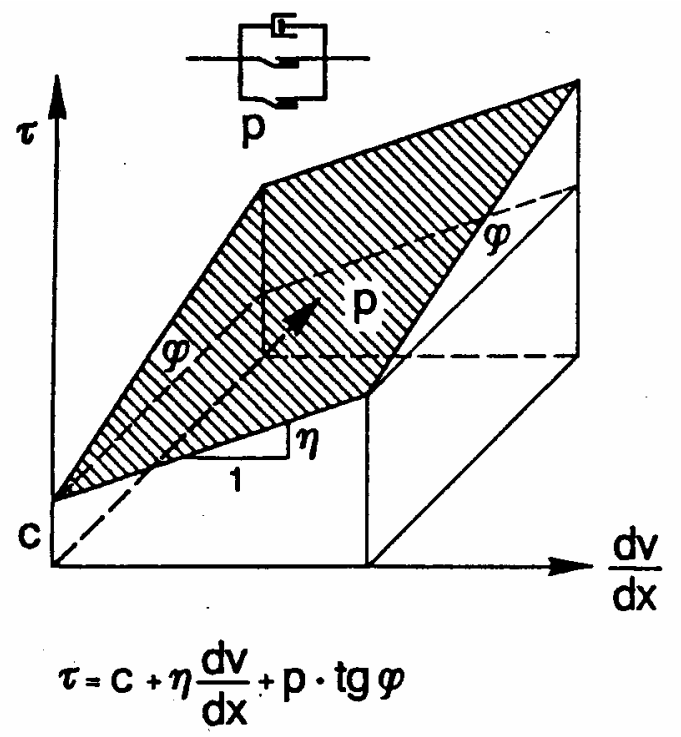

Figure 2: Rheological Behavior for a Binghamian Body with internal friction (De Paoli et al., 1992). 
Grouts to combat active flow conditions have higher viscosity and cohesion that enhance antiwashout characteristics. The high cohesion is not disadvantageous in such circumstances, since penetration of small apertures is not required in this application.

If the fluid properties of the grout change in an uncontrolled or unpredictable manner with time it is therefore not possible to properly control or analyze the injection process. With the exception of a thixotropic grout, it is typically desirable for a grout to maintain a constant viscosity for a period of time equal to the injection time and then for its viscosity to increase rapidly until initial set is reached. Thixotropic grouts have a low viscosity while being in turbulent motion (being sheared during injection) and much higher viscosity when no shear is applied. This property is beneficial when injecting grouts into open voids because the grout can be placed where it is desired without it flowing away after pumping ceases.

The viscosity of a grout at a given age is typically indexed with a Marsh Funnel for non-sanded grouts and with a flow-cone for sanded grouts. Water has a "Marsh time" of 28 seconds. The procedure for measuring sanded grouts is similar and is described in ASTM C-939. When the Marsh time is in the range of 35 to 50 seconds (low viscosity) good correlation exists between apparent viscosity and true viscosity of the fluid (Deere, 1982). For higher viscosity grouts and partially set grouts, the measurement of cohesion becomes more important. An instrument such as a shear vane, a penetrometer, a Lombardi plate or a Baroid rheometer can be used.

\section{2 $\quad$ Resistance to Pressure Filtration}

Injecting grouts into small apertures is similar to pressing the grout against a filter material. Depending on the formulation of the grout, the water can be forced out, creating a filter cake at the borehole wall. With time, the filter cake makes the formation inaccessible to further injection at that location. HMG resistance to pressure filtration is typically measured with an API filter press. Two tests are possible: measurement of the pressure filtration coefficient $\mathrm{K}_{\mathrm{PF}}$ and measurement of the cake growth coefficient $\mathrm{K}_{\mathrm{pc}}$ (De Paoli et al., 1992). These tests are described in Table 1.

The value of the respective coefficients is then calculated as follows:

$$
\begin{aligned}
& \mathrm{K}_{\mathrm{pf}}\left(\min ^{-1 / 2}\right)=\frac{\text { volume of filtrate }}{\text { volume of sample }} \quad \mathrm{X} \quad \frac{1}{{\text { (time in minutes })^{1 / 2}}^{1}} \\
& \mathrm{~K}_{\mathrm{pc}}\left(\mathrm{mm} \times \min ^{-1 / 2}\right)=(\text { thickness of cake in } \mathrm{mm}) \mathrm{X}_{\frac{1}{(\text { time in minutes })^{1 / 2}}}
\end{aligned}
$$

Resistance to pressure filtration (and hence ability to penetrate) is inversely reflected by the magnitude of the calculated value. The relationship between cohesion and pressure filtration coefficient is shown in Figure 3. Unstable mixes result from the 
high water cement ratios which were common in U.S. practice for decades (e.g. Albritton, 1982).

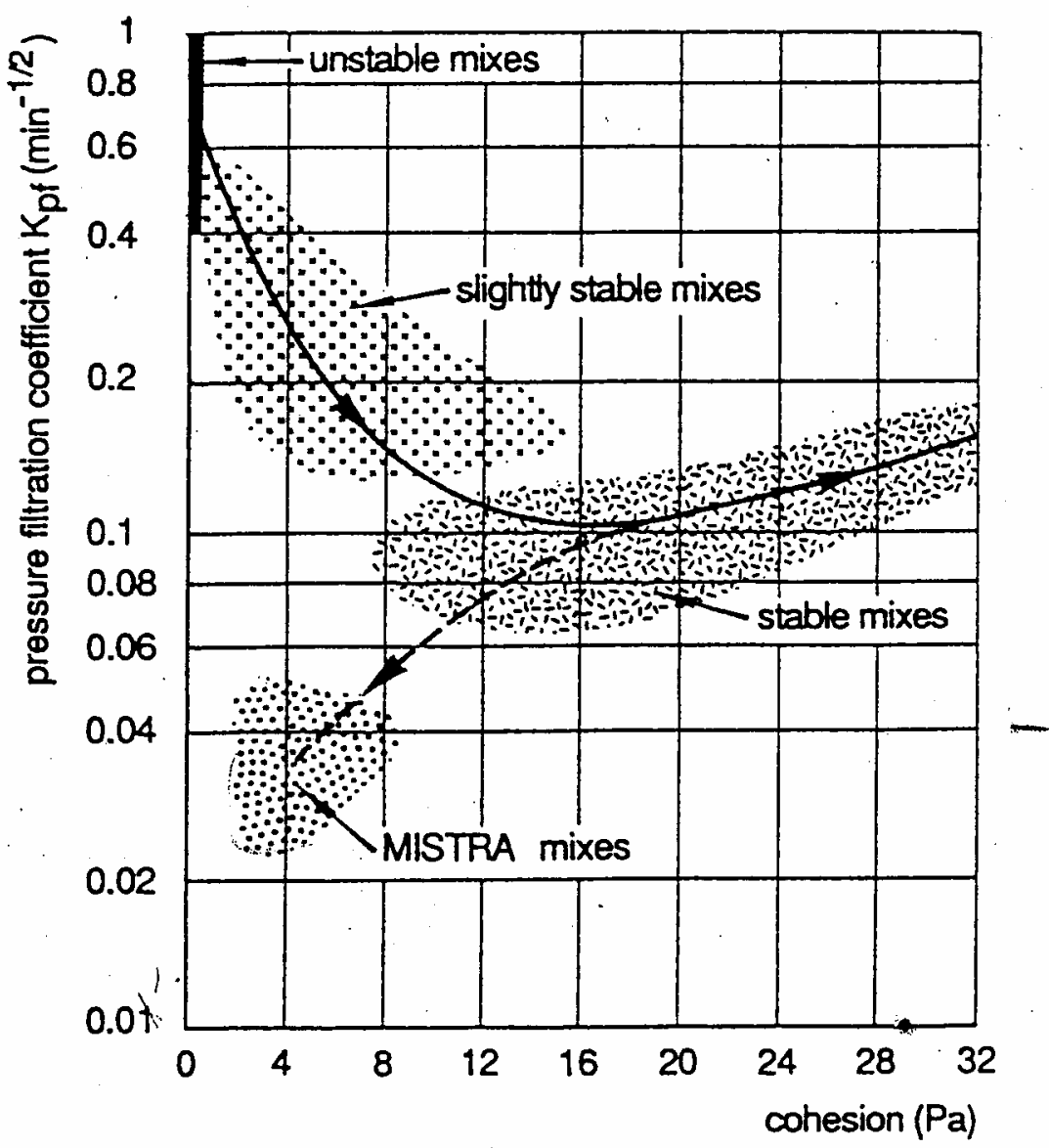

Figure 3. Relationship between resistance to pressure filtration and cohesion for different types of mixes (De Paoli et al., 1992). (Note "MISTRA" refers to a "Modified Stabilized Cement Grout.")

By utilizing combinations of cement additives and water solids ratios pressure filtration coefficients below $0.01 \mathrm{~min}^{-1 / 2}$ can be achieved, while maintaining the apparent viscosity under a 60 second Marsh time: this significantly enhances the penetrability potential of HMGs.

\section{$2.3 \quad \underline{B l e e d}$}

Bleed develops as the cement particles settle due to the effects of gravity and allow free water to develop as a discrete volume. If a grout has high bleed capacity it will not fully fill the pore space within the soil or fractures in a rock due to the bleed water which forms as it sets. Such effects have been demonstrated when using unstable microfine cement grouts in fine sands (Helal and Krizek, 1992). For stable HMGs, bleed should be as low as possible (preferably less than $2 \%$ ), but in no case should be more than $5 \%$. 


\subsection{Water-Repellant/Anti-Washout Characteristics}

If a grout is being placed below the water table, it is undesirable for the grout to disassociate. This characteristic becomes especially important when there is the potential of HMG encountering moving water: it will be diluted, so reducing its effectiveness and potentially posing an environmental threat. Therefore, a grout with good water repellant characteristics is preferable, since it will displace water with minimal dissolution.

Conventional tests to quantify washout resistance are applicable to concretes, and not HMGs. A test for grouts has been specially designed (Gause and Bruce, 1997), wherein a clear plastic chamber allows grout to be placed either in static or dynamic water conditions. The "integrity" of the grout is measured by its efficiency in displacing a known volume of water from the chamber. The lower the volume of grout required to fill the chamber, the better the anti-washout/water repellant characteristics of the grout.

Alternatively, anti-washout characteristics can be evaluated through a series of visually demonstrative, qualitative tests, such as pouring the grout through a column of freestanding water to observe the extent of dispersion of the grout particles. Samples can also be tested by pouring water into a container half filled with grout. With either test, the sample can then be allowed to set so that the amount of laitance/bleed (if any) formed on the surface can be measured. This is a good example of a pragmatic, responsive field test.

\subsection{Prevention of Particle Agglomeration}

The maximum particle size of the hydrated solids in a grout is a key factor that determines the dimensions of soils pores or fractures that can be penetrated. In principle this can be resolved by reducing the particle sizes of the cement, especially the coarse portion. However, if the particles within the suspension are agglomerating during mixing and pumping then the effective maximum particle size is increased and so certain soils or fractures simply become inaccessible. The nature of the particle agglomeration within a mixed HMG can be determined by measuring the particle size distribution in a laboratory by light scattering, absorption or diffraction methods. However, it is not practical to measure it elsewhere directly. An indirect measure is provided by evolution of viscosity with time (as the particles form flocs the viscosity increases). Usually, additives such as super-plasticizer are used to reduce the amount of particle agglomeration (Section 3). 


\section{$2.6 \quad$ Hydration Control}

The ability to accelerate or retard the set of grout is critical for certain grouting applications. When grouting in moving water, an accelerated set time is highly desirable and when inline mixing at the bottom of the hole is conducted, set times lower than 1 minute can be achieved. Conversely, during multiple pass soil grouting, a retarded initial set can be highly desirable, since retarded set times allow multiple passes to be conducted without having to attempt to hydrofracture cured grouts. By retarding the set time it is therefore possible to re-inject certain horizons several times with different formulations, so permitting further penetration and/or densification.

The initial and final set times can be determined with the Vicat needle testing apparatus. The vicat needle is set at the surface of the grout sample and allowed to drop: initial set is reached when the needle only penetrates 1 -inch $(25-\mathrm{mm})$. Final set is determined when the needle does not penetrate the surface of the grout sample.

\subsection{Prevention of Filler Segregation}

For sanded HMG, it is important that the sand within the grout remains suspended and evenly distributed. If the sand falls out of suspension, it does not become part of the grout matrix and furthermore it becomes very difficult to pump the grout. This property can be evaluated through qualitative tests. These tests include sawing a cured sample in half to inspect the distribution of the sand or physically feeling or observing the fluid grout sample after it has been allowed to sit undisturbed for a period of time in a clear walled container.

\subsection{Matrix Porosity of Cured Grout}

Set grouts with low matrix porosity are more durable since water penetration potential is correspondingly reduced. This property is very important for environmental cut-off applications were very low permeabilities are required or when durability and resistance to chemical attack are important. This parameter is measured through triaxial permeability tests. The permeability can be reduced by reducing the water:cement ratio and/or adding materials with a very small particle size such as silica fume. Further details are provided by Littlejohn (1982).

\subsection{Unconfined Compressive Strength.}

It is essential for structural HMGs to achieve their target strength once they have cured. This property can be measured by performing cylinder or grout cube breaks to determine the unconfined compressive strength. Sampling and curing procedures should reflect actual field conditions. 


\section{The Roles of HMG Components}

\subsection{Note on Execution of Tests}

The mixing equipment used for laboratory-testing programs should be selected so that it mimics the intensity and effectiveness of mixing that will result from the production equipment. For example if a high shear colloidal mixer is to be used on site then a small high shear colloidal mixer, or a high shear Hobart type mixer must be used in the laboratory. If agitator trucks are to be used for mixing the grout onsite then a drum mixer is appropriate in the laboratory. The mixer should be sized so that small batches can be prepared and a large number of formulations can be prepared for all tests.

\section{$3.2 \quad$ Materials}

\subsubsection{Cements}

There are several different types of cements available for specific purposes. These include cements with different particle size gradations, and cements chemically formulated to be resistant against specific chemical attack or to provide high early strength. Selecting the appropriate cement type and range of water cement ratios is the initial step in developing a series of site specific HMG formulations. An HMG must have enough solids to be stable and reach an acceptable strength and durability. The use of grouts with high water cement ratios (i.e. greater than 1.5 by weight) is typically disadvantageous due to the resultant reduced injectability, reduced stability, increased bleed, increased matrix porosity and reduced durability. The use of grouts for ground treatment with a water cement ratio of lower then 0.45 by weight is not common due to the high costs and the limitations of mixing and pumping equipment.

Portland cements are the most common and best-known cements used world wide as the basic ingredient for HMGs:

- Type I portland cement is accepted as the general-purpose cement for the majority of grouting projects when the special properties of the other types are not required.

- Type II portland cement is manufactured to resist moderate sulfate attack and to generate a slower rate of heat of hydration than Type I. Type I/II cement is often sold.

- Type III portland cement is used when high early strength is required. It is considered for applications were fast sets are required. Also because it consists of finer particles it can be used to grout slightly smaller apertures than can be penetrated with Type I.

- Type IV portland cement generates less heat during hydration than Type II and develops strength at a slower rate than Type I. It can be used for applications were a large mass of grout will be placed and high hydration temperatures are unacceptable. 
- Type $\mathrm{V}$ portland cement is manufactured for use in grout exposed to severe sulfate action.

- Microfine cements have been ground longer and finer to allow penetration of finer fissures or soil pores. These cements are available with a variety of different properties and may contain blast furnace slag as well as portland cement. They are typically characterized by Blaine Fineness and the maximum particle size. The Blaine fineness is a measure of the specific surface area. Typically the maximum particle size is less than 8 microns, with the bulk of particles under 4 microns with Blaine fineness in excess of $8000 \mathrm{~cm}^{2} / \mathrm{g}$.

\subsubsection{Other Materials}

Formulating a suitable HMG typically involves balancing the potential positive and negative impacts of different additives against each other. It is critical that a laboratory testing program be performed as the interactions between different additives can sometimes be unpredictable. On several occasions, the authors have overcome compatibility issues by simply switching the brand of bentonite being used, or the supplier of Type F Flyash during the lab testing phase of mix design. It is advisable to acquire all the chemical additives from one supplier, to help ensure compatibility.

The most commonly used additives include:

- Super-Plasticizer - Several different types are available including naphthalene sulphonate-, lingo sulphonate,- and melamine-based materials. These chemicals cause each cement particle to adopt a negative charge, and so they electrostatically repel each other. This reduces the viscosity of the grout by inhibiting particle agglomeration. Since the particles are then better dispersed, more surface area is available for hydration, the grout pore space is reduced, and crystals from adjacent particles can interlock more regularly and more strongly. This leads to enhanced strength and durability (Gause and Bruce, 1997). These chemicals also typically retard the initial set of the grout. Typical proportioning is between $0.5 \%$ to $2 \%$ by weight of cement. Ligno sulphonate also acts as a retarder.

- Bentonite - Bentonite stabilizes the grout, increases its resistance to pressure filtration and increases its viscosity. It will reduce the ultimate strength of the grout. Excellent data are provided in Deere (1982) and Littlejohn (1982). There is a wide variety of grades and types of bentonite. However, for most grouting operations, pure, chemically unaltered Wyoming sodium montmorillonite is optimal. The sequence and quality of mixing is critical. During mixing, the dry cement should be added to a pre-hydrated bentonite slurry, since when the cement first comes into contact with the bentonite, the viscosity of the slurry rapidly increases. However, as mixing continues, the HMG becomes less viscous. The initial increase in viscosity is caused by the mutual flocculation of the negatively charged bentonite particles with the positively charged cement particles. The 
reduction in viscosity occurs as the smaller bentonite particles completely coat the cement particles, masking the latter's positive charge (Jefferis, 1982). If high shear mixing is not used or the cement is added too rapidly to the mixer, then it is unlikely that the cement particles will fully disperse as they come into contact with the bentonite. Then flocs of cement particles become coated with bentonite and are difficult to break up (Jefferis, 1982). Bentonite should be hydrated for 12 hours prior to being used unless tests show that equivalent hydration can be achieved with a high shear mixer. Grouts with bentonite that has not been hydrated can be subject to durability problems due to cracking. For HMGs for ground treatment, bentonite should not be used at percentages of higher than $5 \%$ by weight of cement due to its adverse affect on strength.

- Flyash - Both Type C and Type F Flyash are pozzolanic materials, which also improve the particle size distribution of HMGs. They enhance resistance against pressure filtration and increase the durability of the cured grout. Variable amounts of cement replacement can by used for different applications. It is important to note that Type $\mathrm{C}$ Flyash expands and when used in dosages over $20 \%$ can cause durability problems in grouts.

- Silica Fume (Micro Silica) - Silica Fume is a microfine powder ( $<1$ micron) that also improves the particle size distribution of HMGs. It therefore, enhances resistance against pressure filtration, and increases durability and strength of cured grout by reducing its matrix porosity. It also makes the grout more water repellant. Typical proportioning rates are less than $10 \%$ replacement of cement (by weight).

- Welan Gum - Welan gum is a high molecular weight biopolymer. It acts as a thixotropic agent and significantly enhances resistance to pressure filtration. It also increases the cohesion of HMG, which makes the grout slightly more waterrepellant. The dosage required to achieve a particular reduction in pressure filtration coefficient is dependent on the quality of mixing. The better the mixing the more effective the Welan gum is in reducing the pressure filtration coefficient. Welan gum does not reduce the pressure filtration coefficient significantly when used in agitator trucks but does enhance the thixotropy of the grout. Typical proportioning is about $0.1 \%$ to $0.2 \%$ by weight of cement.

- Anti-Washout Agents - A modified cellulose ether such as Master Builder's Rheomac UW450 material significantly enhances resistance to washout, reduces the pressure filtration coefficient, and makes the grout thixotropic. This additive is not compatible with naphthalene sulphonate plasticizer and moderately compatible with Whelan gum and bentonite due to the sharp increase in the HMG viscosity. Typical proportioning is $0.2 \%$ to $1.0 \%$ by weight of cement. 
- Hydration Controls - There are three distinct concepts:

a) Accelerators: There are several different kinds of accelerators the most common of which are sodium silicate and calcium chloride. Calcium chloride must be dissolved prior to adding it to the grout. Although calcium chloride is an efficient accelerator it can have some negative impacts on performance. It may adversely affect sulphate resistance and it can corrode steel (Littlejohn, 1982). Sodium silicate reacts with the calcium ions liberated during initial hydration of the cement to form calcium silicate gel. This reaction causes a rapid increase in the viscosity of the HMG, making the grout very cohesive. This is an exothermic reaction and if high dosages of sodium silicate ( $>20 \%$ by weight of cement) are used, a flash set can be achieved but the resulting cured grout will have low strength and durability. At lower dosages, an initial rise in viscosity occurs but thereafter viscosity remains constant until a rapid set occurs some time later. The cohesiveness of the accelerated grout can provide excellent anti-washout characteristics.

b) Retarders: Extend the gel and set times of grouts in a controllable fashion. Set times of several days are achievable with some of more recent products.

c) Hydration Inhibitors: These are two-component systems involving the use of a stabilizer and an activator. The stabilizer forms a protective coating around the cement particles that stops the hydration process, for up to 72 hours. When the activator is introduced to the grout dissolution of the protective barrier occurs allowing the commencement of hydration and so normal crystal growth (Gause and Bruce, 1997).

\section{Digest of HMG Mix Designs}

There has been a rapidly growing number of cases in the United States where multicomponent HMGs have been successfully used in a wide variety of applications and conditions. Space restrictions prevent even summary descriptions of the mix design logic. Nevertheless, the authors thought it would be useful to provide examples of typical HMGs used recently in certain major projects (Table 2).

Table 2: Summary of projects for which HMG mix designs are provided.

\begin{tabular}{|c|c|c||}
\hline PROJECT & PURPOSE OF GROUTING & MAIN REFERENCE \\
\hline $\begin{array}{c}\text { Oak Ridge } \\
\text { National Laboratory, TN }\end{array}$ & $\begin{array}{c}\text { To encapsulate radio-active } \\
\text { waste contained in trenches via } \\
\text { multiple injections }\end{array}$ & $\begin{array}{c}\text { Berry and Narduzzo, } \\
1997\end{array}$ \\
\hline Penn Forest Dam, PA & $\begin{array}{c}\text { Rock mass curtain grouting of } \\
\text { dam foundation }\end{array}$ & $\begin{array}{c}\text { Wilson and Dreese, } \\
1998\end{array}$ \\
\hline Tims Ford Dam, TN & $\begin{array}{c}\text { Remedial curtain in karstic } \\
\text { limestone to reduce 8000 gpm } \\
\text { seepage }\end{array}$ & $\begin{array}{c}\text { Bruce, Hamby and } \\
\text { Henry, 1998 }\end{array}$ \\
\hline Limestone Quarry, WV & $\begin{array}{c}\text { Curtain in karstic limestone to } \\
\text { cut-off 40,000 gpm seepage }\end{array}$ & $\begin{array}{c}\text { Bruce, Traylor and } \\
\text { Lolcama, 2001 }\end{array}$ \\
\hline
\end{tabular}


Details of the mix designs used in these projects are provided in Tables 3 to 6 , respectively. It must be noted that in each case, the HMG design was tailored to the specific site conditions and project goals.

Table 3: Mix designations and properties for HMG mixes at ORNL.

\begin{tabular}{|c|c|c|c|c|c|}
\hline \multirow{2}{*}{ MATERIAL } & \multicolumn{5}{|c|}{ Mix DESIGNATION } \\
\hline & MF & MIX W & MIX E & MIX K & MIX T \\
\hline Water $(\mathrm{lbs} / \mathrm{Kg})$ & $100 / 45.5$ & $100 / 45.5$ & $100 / 45.5$ & $100 / 45.5$ & $100 / 45.5$ \\
\hline Bentonite (lbs/Kg) & $2 / 0.9$ & $2 / 0.9$ & $3 / 1.4$ & $5 / 2.3$ & $7 / 3.2$ \\
\hline Silica Fume (lbs/Kg) & $5 / 2.3$ & $6 / 2.7$ & $6 / 2.7$ & $6 / 2.7$ & $6 / 2.7$ \\
\hline $\begin{array}{l}\text { Type F FlyAsh } \\
\text { (lbs/Kg) }\end{array}$ & 0 & 0 & 0 & 0 & $10 / 4.5$ \\
\hline Pumice (lbs/Kg) & $13 / 5.9$ & $8 / 3.6$ & $16 / 7.3$ & $16 / 7.3$ & $16 / 7.3$ \\
\hline $\begin{array}{l}\text { Ligno-Sulphonate } \\
\text { - Retarder (lbs/Kg) }\end{array}$ & $0.5 / 0.2$ & $0.8 / 0.4$ & $1 / 0.5$ & $1.4 / 0.6$ & $2 / 0.9$ \\
\hline Welan Gum (lbs/Kg) & $0.05 / 0.02$ & $0.05 / 0.02$ & $0.08 / 0.004$ & $0.08 / 0.004$ & $0.08 / 0.004$ \\
\hline $\begin{array}{l}\text { High Early Cement } \\
(\mathrm{lbs} / \mathrm{Kg})\end{array}$ & 0 & $50 / 20$ & $80 / 40$ & $80 / 40$ & $80 / 40$ \\
\hline $\begin{array}{l}\text { Microfine Cement } \\
\quad(\mathrm{lbs} / \mathrm{Kg})\end{array}$ & $65 / 30$ & 0 & 0 & 0 & 0 \\
\hline Specific Gravity & 1.41 & 1.28 & 1.43 & 1.44 & 1.49 \\
\hline Flow Cone (Sec) & 34 & 35 & 45 & 45 & 51 \\
\hline Shear Vane $(\mathrm{Pa})$ & $\begin{array}{l}333 @ \\
18 \mathrm{hrs}\end{array}$ & $\begin{array}{c}0 @ \\
18 \mathrm{hrs}\end{array}$ & $\begin{array}{c}1000 @ \\
18 \mathrm{hrs}\end{array}$ & $\begin{array}{l}360 @ \\
24 \mathrm{hrs}\end{array}$ & $\begin{array}{l}573 @ \\
24 \mathrm{hrs}\end{array}$ \\
\hline $\begin{array}{c}\text { Brookfield Viscosity } \\
\operatorname{Mtr}(\mathrm{Pa})\end{array}$ & 90 & 550 & 720 & 350 & $\begin{array}{c}\text { No } \\
\text { reading. }\end{array}$ \\
\hline $\begin{array}{c}\text { Initial Set@20C (hrs) } \\
\text { Vicat }\end{array}$ & 104 & 85 & 93 & $\begin{array}{c}\text { No } \\
\text { Measure }\end{array}$ & 186 \\
\hline $\mathrm{KPF} \times 10^{-3}(\mathrm{~min})^{-1 / 2}$ & 2.75 & 37.7 & 4.2 & 3.6 & 3.8 \\
\hline
\end{tabular}

Note that these mixes were prepared in a production scale mixer in large batches to verify the properties obtained earlier during bench scale tests.

$\mathrm{MF}$ - microfine, $\mathrm{W}, \mathrm{E}, \mathrm{K}, \mathrm{T}$ - regular cement 
Table 4: Mix designations and properties for HMG mixes at Penn Forest Dam, PA.

\begin{tabular}{|c|c|c|c|c|}
\hline \multirow{2}{*}{ MATERIAL } & \multicolumn{4}{|c|}{ Mix DESIGNATION } \\
\hline & $\mathbf{A}$ & B & $\mathbf{C}$ & $\mathrm{C}+$ \\
\hline Water (lbs/Kg) & $210 / 95$ & $165 / 75$ & $120 / 55$ & $120 / 55$ \\
\hline $\begin{array}{l}\text { 8\% Bentonite Slurry } \\
\text { (Gal/Liters) }\end{array}$ & $8 / 30$ & $8 / 30$ & $8 / 30$ & $8 / 30$ \\
\hline Portland Cement (lbs/Kg) & $188 / 85$ & $188 / 85$ & $188 / 85$ & $188 / 85$ \\
\hline Type F FlyAsh (lbs/Kg) & $80 / 36$ & $80 / 36$ & $80 / 36$ & $80 / 36$ \\
\hline Welan Gum (lbs/Kg) & $0.22 / 0.1$ & $\begin{array}{c}0.22 / 0 . \\
1\end{array}$ & $0.22 / 0.1$ & $0.22 / 0.1$ \\
\hline Super Plasticizer (oz/liter) & $45 / 1.4$ & $45 / 1.4$ & $30 / 0.9$ & $30 / 0.9$ \\
\hline Sodium Silicate (gal/liter) & & & & $4 / 20$ \\
\hline Accelerator (gal/liter) & & & & $2-5$ \\
\hline Yield (gal/liter) & $44 / 168$ & $38 / 148$ & $33 / 128$ & $40 / 150$ \\
\hline Specific Gravity & 1.49 & 1.55 & 1.64 & 1.58 \\
\hline Marsh Cone (Sec) & $45-50$ & $70-80$ & $>120$ & \\
\hline Flow Cone (Sec) & & & 20 & \\
\hline Bleed at 3 hours (\%) & 1 & 0 & 0 & 0 \\
\hline Initial Set (hrs) & $2-3$ & $1-3$ & $1-2$ & 0.016 \\
\hline Final Set (hrs) & $5-6$ & $4-6$ & $3-5$ & \\
\hline $\mathrm{KPF} \times 10^{-3}(\mathrm{~min})^{-1 / 2}$ & 0.05 & 0.05 & 0.05 & 0.05 \\
\hline
\end{tabular}

Table 5: Mix designations and properties for HMG mixes at Tims Ford Dam, TN.

\begin{tabular}{|c|c|c|c|c|}
\hline \multirow{2}{*}{ Material } & \multicolumn{4}{|c|}{ Mix DESIGNATION } \\
\hline & MIX A & MIX B & MIX C & MIX D \\
\hline Water $(\mathrm{lbs} / \mathrm{kg})$ & $141 / 64$ & $141 / 64$ & $94 / 42$ & $94 / 42$ \\
\hline Bentonite (lbs/kg) & $4.7 / 2.1$ & $9.4 / 4.2$ & $4.7 / 2.1$ & $4.7 / 2.1$ \\
\hline Cement (lbs/kg) & $94 / 64$ & $94 / 64$ & $94 / 64$ & $94 / 64$ \\
\hline Rheobuild 2000B (oz/liter) & $15 / 0.5$ & $30 / 0.9$ & $20 / 0.6$ & $20 / 0.6$ \\
\hline Rheomac UW450 (oz/liter) & 0 & 0 & 0 & $5 / 0.2$ \\
\hline Specific Gravity & 1.39 & 1.40 & 1.53 & 1.53 \\
\hline Bleed $(\%)$ & $<5$ & $<1$ & $<1$ & 0 \\
\hline $\mathrm{KPF} \times 10^{-3}(\min )^{-1 / 2}$ & $<104$ & $<42$ & $<42$ & $<42$ \\
\hline Comp Strength@28D (PSI) & 500 & 500 & 800 & 800 \\
\hline Flow Cone $(\mathrm{Sec})$ & 35 & 50 & $60+$ & $100+$ \\
\hline Stiffening Time (hh:mm) & $4: 30$ & $4: 30$ & 4:00 & $4: 00$ \\
\hline Hardening Time (hh:mm) & $10: 30$ & $8: 30$ & $8: 00$ & $8: 00$ \\
\hline Thickening and Thinning & \multicolumn{4}{|c|}{ Mix Designation } \\
\hline Additional Bentonite (gal/liter) & $8 / 32$ & $16 / 64$ & $8 / 32$ & $8 / 32$ \\
\hline Additional Water (gal/liter) & $9.9 / 39$ & $2.8 / 11$ & $4.2 / 16$ & $4.2 / 16$ \\
\hline
\end{tabular}


Table 6: Mix designations and properties for HMG mixes at Limestone Quarry, WV.

\begin{tabular}{|l|c|c|c|c|c|}
\hline \multirow{2}{*}{ Material } & \multicolumn{5}{c|}{ Mix Designation } \\
\cline { 2 - 6 } & $\mathrm{A} 0$ & $\mathrm{~A} 1$ & $\mathrm{~A} 2$ & $\mathrm{~A} 3$ & $\mathrm{~A} 4$ \\
\hline Water (lbs/kg) & $82 / 310$ & $106 / 401$ & $103 / 390$ & $105 / 397$ & $102 / 386$ \\
\hline $\begin{array}{l}\text { 8\% Bentonite Slurry } \\
\text { (Gal/Liters) }\end{array}$ & $68 / 257$ & $20 / 76$ & $26 / 98$ & $26 / 98$ & $25 / 95$ \\
\hline Cement (lbs/kg) & $729 / 331$ & $856 / 389$ & $878 / 399$ & $895 / 406$ & $866 / 393$ \\
\hline Flyash (lbs/kg) & $638 / 290$ & $749 / 340$ & $768 / 349$ & $783 / 355$ & $866 / 393$ \\
\hline $\begin{array}{l}\text { Rheobuild 2000B } \\
\text { (oz/liter) }\end{array}$ & $62 / 1833$ & $73 / 2159$ & $74 / 2188$ & $76 / 2247$ & $73 / 2159$ \\
\hline $\begin{array}{l}\text { Rheomac UW450 } \\
\text { (oz/liter) }\end{array}$ & $19 / 562$ & $22 / 651$ & $22 / 651$ & $23 / 680$ & $22 / 651$ \\
\hline Specific Gravity & 1.53 & 1.55 & 1.60 & 1.63 & 1.64 \\
\hline Bleed (\%) & 0 & 5.5 & 3.5 & 2 & 2 \\
\hline Marsh Time & 55 & $80+$ & $120+$ & N/A & N/A \\
\hline
\end{tabular}

\section{Final Remarks}

Although balanced, stabilized HMGs have been used in Europe for far longer, it is only since the late 1990's that their efficiency and effectiveness has been exploited in the U.S. However, the success of several high profile projects when using such HMGs has driven a rapid acceptance of the logic and principles involved. Perhaps the clearest indicator of this has been the fact that one of the industry's largest "users" - the US Army Corps of Engineers - has fully embraced the concepts to the extent that the use of multicomponent HMGs is now standard. Major projects in the private sector are being similarly executed.

\section{References}

Albritton J.A., (1982). "Cement Grouting Practices US Army Corps of Engineers." Proceedings of the ASCE Specialty Conference in Grouting in Geotechnical Engineering, New Orleans, Louisiana, pp. 264-278.

Berry, R.M. and Narduzzo, L., (1997). "Radioactive Waste Trench Grouting - A Case History of Oak Ridge National Laboratory Grouting"- Grouting - Compaction, Remediation, and Testing, Proc. of Sessions Sponsored by the Grouting Committee of the Geo-Institute of the American Society of Civil Engineers, Logan UT, Ed. by C. Vipulanandan, Geotechnical Special Publication No. 66, July 16-18, pp. 76-89.

Bruce, D.A., Hamby, J.A. and Henry, J.F., (1998) "Tims Ford Dam, Tennessee: Remedial Grouting of Right Rim”. Proc. Annual Conference, Dam Safety 1998, Association of State Dam Safety Officials, Las Vegas, NV, Oct. 11-14, 13 pp.

Bruce, D.A., R.P. Traylor, and J. Lolcama. (2001). "The Sealing of a Massive Water Flow through Karstic Limestone." Foundations and Ground Improvement, 
Proceedings of a Specialty Conference, American Society of Civil Engineers, Blacksburg, VA, June 9-13, Geotechnical Special Publication No. 113, pp. 160-174.

Byle, M.J. (1997). "Limited Mobility Displacement Grouting: When "Compaction Grout" is NOT Compaction Grout", Grouting - Compaction, Remediation, and Testing, Proc. of Sessions Sponsored by the Grouting Committee of the Geo-Institute of the American Society of Civil Engineers, Logan UT, Ed. by C. Vipulanandan, Geotechnical Special Publication No. 66, July 16-18, pp. 32-42.

Deere, D.U. (1982), “Cement-Bentonite Grouting For Dams," Proceedings of the ASCE Specialty Conference in Grouting in Geotechnical Engineering, New Orleans, Louisiana, pp. 279-300.

De Paoli, B., Bosco, B., Granata, R. and Bruce, D.A. (1992). "Fundamental Observations on Cement Based Grouts (1): Microfine Cements and the Cemill Process." Proc. ASCE Conference, "Grouting, Soil Improvement and Geosynthetics”, New Orleans, LA,. Feb. 25-28, 2 Volumes, pp. 474-485.

Gause, C.C. and D.A. Bruce. (1997). "Control of Fluid Properties of Particulate Grouts: Part 1 - General Concepts." Grouting - Compaction, Remediation, and Testing, Proc. of Sessions Sponsored by the Grouting Committee of the Geo-Institute of the American Society of Civil Engineers, Logan UT, Ed. by C. Vipulanandan, Geotechnical Special Publication No. 66, July 16-18, pp. 212-229.

Helal, A.M and Krizek, (1992), "Preferred Orientation of Pore Structure In CementGrouted Sand," Proceedings of the ASCE Specialty Conference in Grouting in Geotechnical Engineering, New Orleans, Louisiana, pp 526-540.

Jefferis, S.A., (1982), "Effects of Mixing On Bentonite Slurries and Grouts," Specialty Conference in Grouting in Geotechnical Engineering, New Orleans, Louisiana, Feb. 10 to 12, pp. 62-77.

Littlejohn, G.S. (1982), "Design of Cement Based Grouts," Proceedings of the ASCE Specialty Conference in Grouting in Geotechnical Engineering, New Orleans, Louisiana, Feb. 10 to 12, pp. 35-48.

Lombardi, G., (1985). "The Role of Cohesion in Cement Grouting of Rock," $15^{\text {th }}$ ICOLD Congress. Lausanne, Switzerland, Q58, 13 p.

Wilson, D. and Dreese, T. (1998). "Grouting Technologies for Dam Foundations," Proceedings of the 1998 Annual Conference Association of State Dam Stafety Officials, October 11-14, Las Vegas, Neveda, Paper No. 68. 
Keywords: High Mobility Grout, Cement Based Suspension Grout, Slurry Grout, Microfine Cement, Super Plasticizer, Flyash, Silica Fume, Retarder, Accelerator, Bentonite, Whelan Gum, Marsh Cone, Filter Press, Mud Balance, Shear Vane, Cohesion, Initial Set, Final Set, Viscosity, Matrix Porosity, Stable, Balanced. 